\title{
Análise dos resultados do Exame Nacional de Desempenho de Estudantes (Enade) para Educação a Distância do ciclo 2015 a 2017
}

Analysis of the Results of the National Exam for the Performance of Students for Distance Education from the 2015 to 2017 Cycle

\section{Carlos Eduardo Bielschowsky}

Universidade Federal do Rio de Janeiro (UFRJ), Instituto de Química, Rio de Janeiro - RJ. Fundação Cecierj / Consórcio Cederj - Centro de Ciências e Educação Superior a Distância do Estado do Rio de Janeiro. biel@cecierj.edu.br

\section{Resumo}

Em 2017 completamos um primeiro ciclo de três anos do Exame Nacional de Desempenho de Estudantes (Enade), o que envolve todas as carreiras, com 175.543 alunos participantes de 877 cursos de Educação a Distância (EaD), pertencendo a um total de 144 diferentes instituições de Ensino Superior. Observou-se forte crescimento do número de polos entre 2016 e 2017, tendência que provavelmente irá se sustentar em 2018. Alguns fatos foram especialmente notórios: o baixo crescimento das matrículas nas universidades públicas, quando comparado ao crescimento nas instituições de Ensino Superior (IES) privadas; grande concentração de matrículas $(56,2 \%)$ em apenas cinco das 257 IES públicas e privadas que oferecem Ensino Superior a distância. Observou-se bom desempenho geral das IES que oferecem (EaD), mas baixo desempenho percentual dos alunos, advindos da concentração de alunos em poucas IES com baixo desempenho no Enade. Ao final deste trabalho, relacionamos os principais problemas identificados pela ausência do processo de supervisão dos cursos de EaD, incluindo a necessidade de uma medida mais adequada para avaliar o seu desempenho, e advogamos outras ações urgentes para sanear as distorções encontradas nesta modalidade.

Palavras-chave: Educação superior a distância, Qualidade na educação, Avaliação educacional, Enade, CPC, CGC 


\title{
Analysis of the Results of the National Exam for the Performance of Students for Distance Education from the 2015 to 2017 Cycle
}

\begin{abstract}
In 2017 we completed a first cycle of three years of National Student Performance Test (Enade), which involves all careers, with 175,543 participating students in 877 Distance Education courses, belonging to a total of 144 different institutions of Higher Education. There was a strong increase in the number of poles between 2016 and 2017, a trend that is likely to be sustained in 2018. Some facts were especially noteworthy: low enrollment growth in public universities, when compared to growth in higher education institutions (HEI) private partnerships; (56.2\%) in only five of the 257 public and private HEls offering Distance Higher Education. A good general performance of HEls offered (EaD) was observed, but low percentage performance of students, due to the concentration of students in a few HEls with poor performance in Enade. At the end of this paper, we relate the main problems identified by the absence of the supervision process of the EAD courses, including the need for a more adequate measure to evaluate their performance, and advocate other urgent actions to remedy the distortions found in this modality.
\end{abstract}

Keywords: Higher distance education, Quality in education, Educational evaluation, Enade, CPC, CGC.

\section{Introdução}

O presente trabalho visa atualizar os resultados e discussões apresentadas recentemente (Bielschowsky, 2018), incluindo os resultados do Enade de 2017. Naquele recente artigo também contextualizamos a questão da qualidade da oferta de Educação Superior a Distância (EaD), na visão de associações de diferentes países (ICDE, 2015; Caled; EATU; Chea e Acode), bem como de diferentes autores (Nielsen, 2010; Jarvis, 2014; Quesada, 2015; 2014).

Os dados do censo do Instituto Nacional de Estudos e Pesquisas Educacionais Anísio Teixeira de 2017 (Inep, 2017) já são parcialmente influenciados pelo aumento da oferta de cursos de EaD potencializado pela Portaria Normativa MEC $n^{\circ} 11 / 2017$ (MEC, 2017), regulamentando o Decreto $n^{\circ} 9.057$, de 25 de maio de 2017 (Brasil, 2017). De fato, o censo de 2017 mostra um maior crescimento das matrículas com Educação Superior a Distância, se comparadas aos anos anteriores, alcançando 1,76 milhão de alunos matriculados em 257 instituições de Ensino Superior (IES), contra 1,49 milhão de alunos em 206 IES em 2016. A Tabela 1 compara o número de alunos matriculados, o número de cursos, IES e polos nos últimos cinco anos. 
Tabela 1: Número de alunos, cursos e IES em Educação Superior a Distância (Inep, 2017).

\begin{tabular}{|l|c|c|c|c|c|c|}
\hline & 2012 & 2013 & 2014 & 2015 & 2016 & 2017 \\
\hline $\begin{array}{l}\text { Total de IES } \\
\text { que ofertam } \\
\text { EaD }\end{array}$ & 151 & 166 & 178 & 194 & 206 & 257 \\
\hline $\begin{array}{l}\text { Total de } \\
\text { matrículas } \\
\text { em EaD }\end{array}$ & 1.113 .958 & 1.153 .640 & 1.341 .876 & 1.393 .780 & 1.494 .427 & 1.756 .982 \\
\hline $\begin{array}{l}\text { Matrículas } \\
\text { nas cinco } \\
\text { maiores IES } \\
\text { em EaD }\end{array}$ & 550.095 & 631.049 & 771.345 & 807.922 & 870.311 & 987487 \\
\hline $\begin{array}{l}\text { \% de ma- } \\
\text { trículas em } \\
\text { EaD nas cin- } \\
\text { co maiores }\end{array}$ & 49,40 & 54,70 & 57,50 & 58,00 & 58,20 & 56,20 \\
\hline $\begin{array}{l}\text { Número de } \\
\text { polos }\end{array}$ & 5.432 & 5.327 & 4.912 & 4.915 & 5.133 & 7.050 \\
\hline
\end{tabular}

Observa-se o forte crescimento de 37\% no número de polos entre 2016 e 2017 , tendência que provavelmente irá se manter em 2018. É necessário avaliar o que representa, na prática, o aumento do número de polos, especialmente em face de seu papel como espaços dinamizadores do processo de ensino e aprendizagem.

A Figura 1 compara a evolução das matrículas em cursos presenciais e de EaD desde 2003.

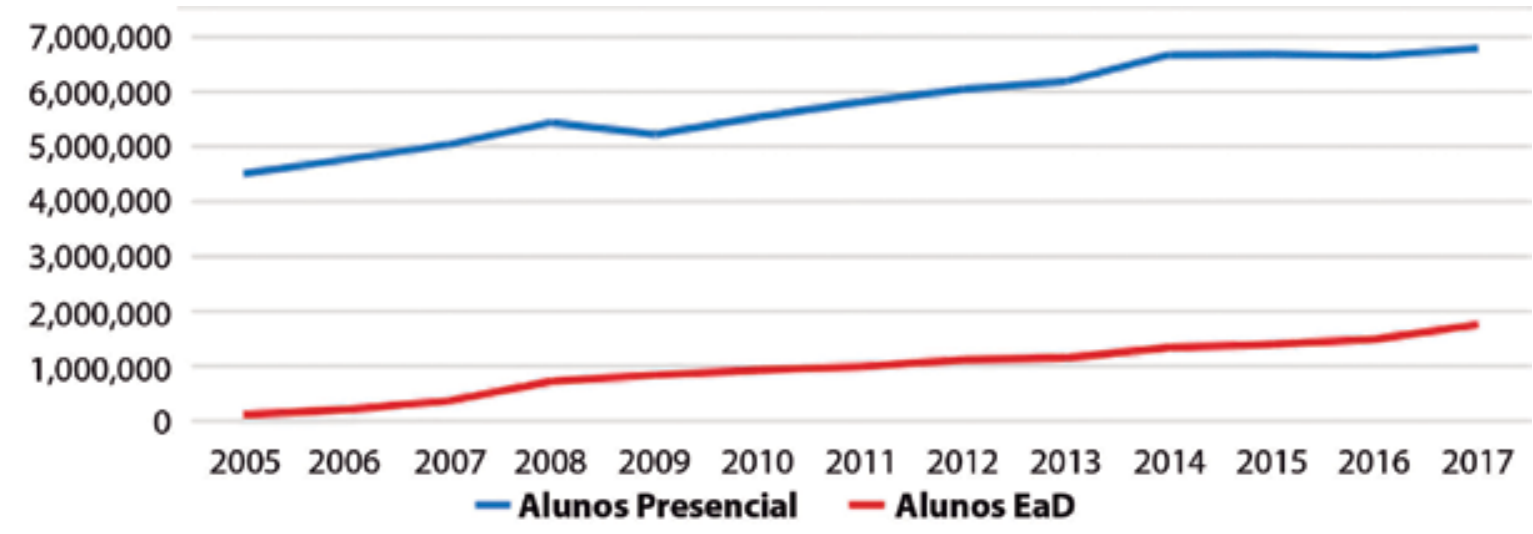

Figura 1: Evolução do número de alunos em cursos presenciais e com EaD desde 2015 (Inep, 2017).

O avanço da EaD é especialmente relevante, pois permite o acesso ao Ensino Superior a uma boa parcela da população que, por diferentes motivos, não consegue estudar em cursos presenciais, seja porque mora em municípios menores onde não existe oferta de Ensino Superior, por questões de mobilidade urbana ou incompatibilidade com o trabalho. Além disso, contribui para o desenvolvimento de novas práticas docentes, não apenas para utilização de recursos digitais, mas por estar historicamente (Petters, 2001) associada a um processo de ensino e aprendizagem focado no aluno, necessitando incorporar a cada dia novas metodologias educacionais, conforme mostram as recomendações da última edição do Horizon Report (Adams Becker et al., 2017).

A Educação a Distância vem sendo um dos principais motores do crescimento do Ensino Superior no país: em 2017 tínhamos 8.286.663 alunos em cursos superiores contra 4.567.798 alunos matriculados em 2005, um crescimento de 3.718 .864 alunos, dos quais 44\% (1.642.340) em EaD. Esse crescimento permitiu 
ao Brasil alavancar melhores posições no ranking internacional de envolvimento no Ensino Superior, conforme já destacamos (Bielschowsky, 2018).

Esses consideráveis avanços, entretanto, vêm sendo desiguais, como mostra a Figura 2, que compara a evolução do número de alunos matriculados em instituições públicas e privadas, dando destaque às cinco IES com maior número de alunos.

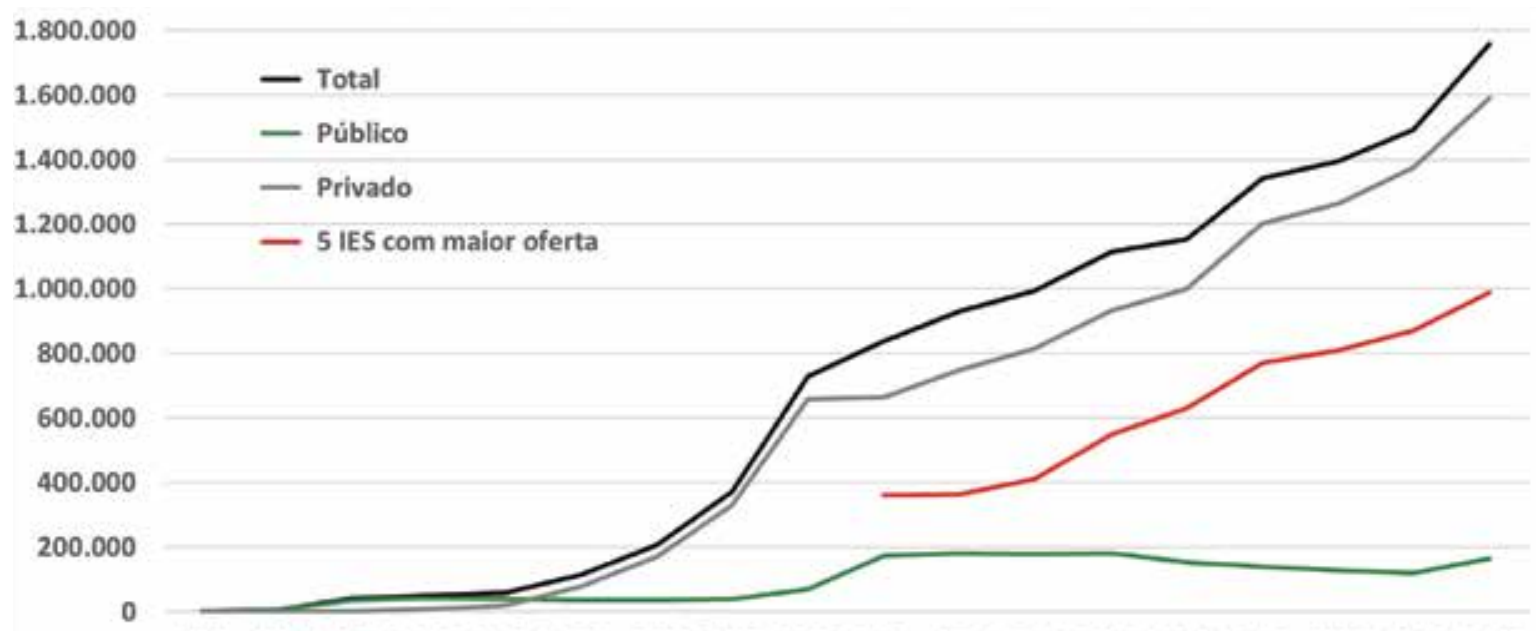

200020012002200320042005200620072008200920102011201220132014201520162017

Figura 2: Evolução das matrículas em EaD de instituições públicas e privadas desde 2000.

Dois fatos são especialmente notórios na Figura 2: o baixo crescimento das matrículas nas universidades públicas, quando comparado ao crescimento nas IES privadas; a forte concentração de matrículas (56\%) em apenas cinco das 257 IES, públicas e privadas, que oferecem ensino superior à distância. Qual a consequência da forte concentração de matrículas em poucas IES? Como auferir seu impacto na qualidade da EaD?

Em uma publicação recente (Bielschowsky, 2018), mostramos que o Conceito Provisório de Curso (CPC) e o Conceito Geral de Cursos (CGC) não são minimamente adequados para auferir cursos de EaD, sinteticamente por dois motivos principais:

i. $30 \%$ do peso do Conceito Provisório de Curso refere-se a qualificação e regime de trabalho dos professores (7,5\% para proporção de mestres, 15\% para proporção de Doutores e 7,5\% para regime de trabalho). Não leva em conta, portanto, a qualificação dos tutores nem a relação professor e tutor/aluno. Ademais, a média da relação aluno/professor das cinco IES com maior oferta é de 199, contra 45 alunos por professor das demais IES que oferecem EaD. Chegamos a encontrar cursos de EaD com mais de 400 alunos por professor.

ii. 35\% do peso do CPC refere-se ao Indicador de Diferença entre os Desempenhos (IDD). Mostramos que o IDD não funciona para resultados do Enade inferiores a 1,945, que correspondem aos conceitos Enade discretos 1 e 2.

Como consequência, o Conceito Geral de Curso (CGC), fortemente pautado no Conceito Provisório de Curso (CPC) e em outras variáveis mais globais, tampouco é adequado aos cursos de EaD. Para complicar ainda mais o problema, o Ministério da Educação (MEC) desde 2011 deixou de fazer supervisão por pares em cursos de EaD, mesmo com indícios de irregularidades.

Restam os resultados do Enade que, embora pautados em apenas um exame e não contemplem outros elementos da oferta, são hoje o principal instrumento disponível para auferir a qualidade dos cursos de graduação, especialmente em EaD; o conceito Enade não relaciona uma "nota" absoluta dos cursos, mas a posição relativa em comparação aos demais cursos avaliados. 


\section{Resultados do Enade}

\subsection{Resultados globais para o ciclo Enade 2015-2017}

Apenas a partir de 2015 o Inep passou a disponibilizar os dados do Enade separando os cursos presenciais dos cursos em EaD. Como determinado curso é avaliado apenas a cada três anos, só em 2017 completou-se um primeiro ciclo com resultados de todos os cursos separando os resultados da EaD daqueles dos cursos presenciais.

A Tabela 2 mostra, por ano, o número de cursos e IES cujos alunos de EaD fizeram o Enade e o número total de alunos participantes do Enade de cada curso. Mostra também a soma de cursos e de alunos que participaram do Enade no ciclo 2015-2017, bem como o número de IES cujos alunos participaram do Enade de um ou mais cursos nesse período. Consideramos, no presente estudo, apenas as IES privadas e as IES públicas federais e estaduais ( $99,8 \%$ dos alunos de EaD em 2017) e IES que tenham tido, num determinado ano, mais que cinco alunos avaliados no Enade.

Tabela 2: Número de IES, cursos e alunos participantes dos exames Enade de 2015 a 2017.

\begin{tabular}{|c|c|c|c|c|c|c|}
\hline & $\begin{array}{l}\text { Número de } \\
\text { IES }\end{array}$ & $\begin{array}{l}\text { Número de } \\
\text { cursos }\end{array}$ & $\begin{array}{c}\text { Alunos } \\
\text { participantes }\end{array}$ & $\begin{array}{l}\text { Número de } \\
\text { IES }\end{array}$ & $\begin{array}{c}\text { Número de } \\
\text { cursos }\end{array}$ & $\begin{array}{c}\text { Alunos } \\
\text { participantes }\end{array}$ \\
\hline & \multicolumn{3}{|c|}{2015} & \multicolumn{3}{|c|}{2016} \\
\hline IES públicas federais & 21 & 26 & 1.773 & 1 & 2 & 120 \\
\hline IES públicas estaduais & 10 & 11 & 1.238 & 0 & 0 & 0 \\
\hline IES privadas & 69 & 316 & 64.628 & 29 & 49 & 17.711 \\
\hline \multirow[t]{2}{*}{ Total } & 100 & 353 & 67.639 & 30 & 51 & 17.831 \\
\hline & \multicolumn{3}{|c|}{2017} & \multicolumn{3}{|c|}{ Ciclo 2015-2017 } \\
\hline IES públicas federais & 41 & 136 & 7.899 & 46 & 164 & 9.792 \\
\hline IES públicas estaduais & 11 & 30 & 2.683 & 14 & 41 & 3.921 \\
\hline IES privadas & 69 & 305 & 79.479 & 84 & 670 & 161.818 \\
\hline Total & 121 & 471 & 90.061 & 144 & 875 & 175.531 \\
\hline
\end{tabular}

Os resultados do Enade são oferecidos de duas maneiras: em uma faixa contínua que vai de 0 a 5,00; ou como Enade discreto, diretamente relacionado à primeira, como a tabela abaixo.

Tabela 3: Relação entre os conceitos contínuo e discreto do Enade/Inep.

\begin{tabular}{|l|c|c|c|c|c|}
\hline $\begin{array}{c}\text { Conceito Enade } \\
\text { discreto }\end{array}$ & 1 & 2 & 3 & 4 & 5 \\
\hline $\begin{array}{l}\text { Faixa do conceito } \\
\text { Enade contínuo }\end{array}$ & 0 a 0,98 & 0,98 a 1,97 & 1,98 a 2,97 & 2,98 a 3,97 & 3,98 a 5,00 \\
\hline
\end{tabular}


Mostramos anteriormente (Bielschowsky 2018) que, dada a forte concentração de alunos em algumas IES, a simples média dos conceitos Enade dos cursos não representa de forma adequada o desempenho dos alunos; por esse motivo, introduzimos o Enade proporcional ao número de alunos, dado por:

- Enade proporcional (IES, EaD, ano) $=\sum$ (cursos EaD) Enade (IES, curso, ano) * Nparticipantes (curso, IES, ano)] / $\sum$ (cursos) Nparticipantes (curso, IES, ano)

Introduzimos também o conceito de média proporcional do ano, como a média sobre o Enade proporcional acima descrito:

- Enade proporcional médio EaD (ano) $=\sum$ (IES) Enade proporcional (IES, EaD, ano) / $\sum$ (IES) Nparticipantes (IES EaD, ano)]

Vejamos agora os resultados do Enade para o ciclo 2015-2017. A Tabela 4 compara o Enade médio com o Enade proporcional para todos os cursos presenciais e com EaD avaliados nesse ciclo.

Tabela 4: Enade médio e Enade proporcional para o ciclo 2015-2017.

\begin{tabular}{|l|c|c|c|c|}
\hline & \multicolumn{2}{|c|}{ Enade médio } & \multicolumn{2}{c|}{ Enade proporcional } \\
\hline & Presencial & EaD & Presencial & 1,84 \\
\hline 2015 & 2,37 & 2,42 & 2,40 & 1,54 \\
\hline 2016 & 2,49 & 1,99 & 2,46 & 1,89 \\
\hline 2017 & 2,42 & 2,08 & 2,41 & 1,84 \\
\hline
\end{tabular}

Esses resultados mostram um Enade médio de todas as IES e para os três anos acima do valor de 1,945, ou seja, oferecendo para EaD como um todo um conceito discreto três para todas as categorias. O mesmo não ocorre com o Enade proporcional, que é inferior a 1,945 (conceito discreto três) em todos os anos. Essa diferença decorre da concentração de matrículas em EaD em IES com baixo desempenho no Enade, conforme mostraremos mais adiante.

A Tabela 5 compara os resultados do Enade proporcional de EaD com o presencial, por categoria administrativa, para o ciclo 2015-2017.

Tabela 5: Enade proporcional por modalidade educacional e por categoria administrativa.

\begin{tabular}{|c|c|c|c|c|c|c|c|c|}
\hline \multirow[b]{4}{*}{ Privada } & \multicolumn{8}{|c|}{ Enade proporcional } \\
\hline & \multicolumn{2}{|c|}{2015} & \multicolumn{2}{|c|}{2016} & \multicolumn{2}{|c|}{2017} & \multicolumn{2}{|c|}{ Ciclo 2015-2017 } \\
\hline & Presencial & EaD & Presencial & EaD & Presencial & EaD & Presencial & EaD \\
\hline & 2,26 & 1,83 & 2,20 & 1,54 & 2,10 & 1,85 & 2,20 & 1,81 \\
\hline Pública & 2,93 & 1,10 & 3,11 & - & 2,49 & 2,31 & 2,68 & 1,93 \\
\hline Pública & 3,45 & 2,52 & 3,30 & 1,95 & 3,01 & 2,11 & 3,15 & 2,19 \\
\hline Todas & 2,31 & 1,84 & 2,32 & 1,54 & 2,20 & 1,85 & 2,40 & 1,84 \\
\hline
\end{tabular}


Esses dados mostram que os resultados do Enade proporcional ao número de alunos para EaD estão inferiores àqueles dos cursos presenciais para todas as três categorias administrativas. As IES públicas federais e estaduais apresentam nos três anos um Enade proporcional superior a 1,945 (conceito discreto 3), exceto as IES públicas estaduais no Enade 2015. Chama a atenção o baixo conceito Enade proporcional das IES públicas estaduais de 2015, quando foram avaliados principalmente alunos dos cursos de Administração e Administração Pública. Os resultados apresentam grandes variações entre as diferentes IES públicas estaduais e federais, conforme mostra a Figura 3.
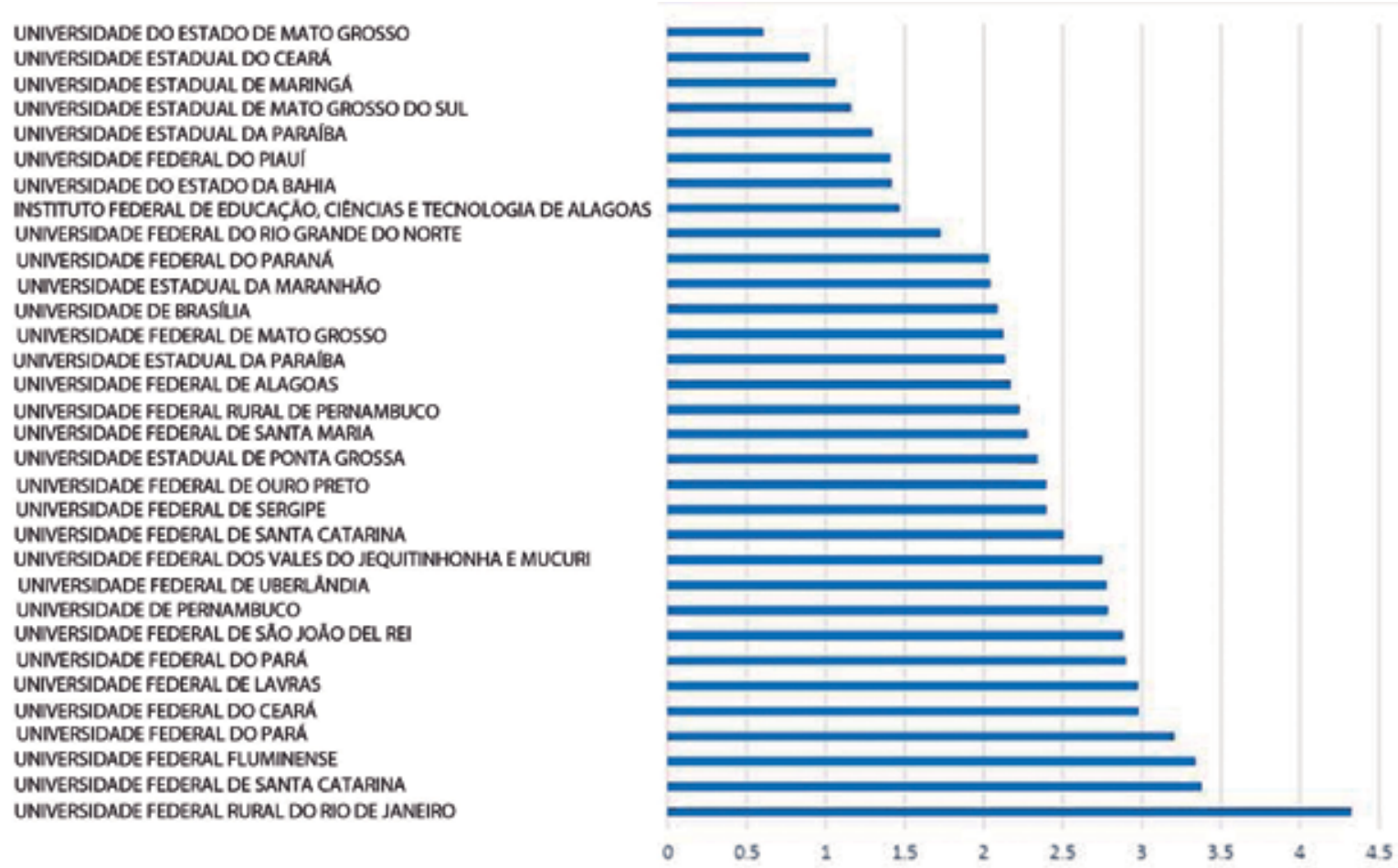

Figura 3: Notas do Enade para os cursos de Administração e Administração Pública das IES públicas.

A Figura 3 mostra que, das 31 IES públicas com cursos de Administração e Administração Pública avaliados em 2015, apenas uma alcançou conceito Enade discreto 5; quatro alcançaram conceito 4, 17 obtiveram conceito 3 e oito ficaram com conceito 2. Cabe pesquisar os motivos dessas diferenças.

Embora algumas IES apresentem resultados preocupantes para o Enade proporcional dos cursos de EaD, essa não é uma característica inerente da modalidade, como mostra a comparação do Enade proporcional para o conjunto dos cursos das sete IES que compõem o Consórcio Cederj no Rio de Janeiro (CEFET, IFF, UENF, UERJ, UNIRIO, UFF, UFRJ e UFRRJ).

Tabela 6: Enade proporcional para os cursos das IES que compõem o Consórcio Cederj.

\begin{tabular}{|c|c|c|c|c|}
\hline & \multicolumn{2}{|c|}{$\begin{array}{c}\text { Enade proporcional de 2015 das IES } \\
\text { do Consórcio Cederj }\end{array}$} & \multicolumn{2}{c|}{$\begin{array}{c}\text { Enade proporcional de 2017 das IES } \\
\text { do Consórcio Cederj }\end{array}$} \\
\cline { 2 - 5 } & Presencial & EaD & Presencial & EaD \\
\hline Enade proporcional & 3,39 & 3,69 & 3,14 & 3,27 \\
\hline Cursos avaliados & 43 & 2 & 82 & 14 \\
\hline
\end{tabular}


O Consórcio Cederj (Bielschowsky, 2017) reúne as IES públicas do Rio de Janeiro e oferece hoje 16 carreiras em 32 polos de apoio presencial, com cerca de 40 mil alunos ativos. Embora os resultados de 2015 para a EaD tenham sido excelentes (dois cursos avaliados, um com conceito 4 e outro com 5), ainda não indicavam uma tendência consolidada, pois foram apenas dois cursos avaliados. Os resultados de 2017 já contemplam 14 cursos e indicam claramente que os cursos de EaD do Consórcio têm qualidade equivalente àquela dos cursos presenciais. Não foram obtidos dados para o Enade 2016, já que o Consórcio Cederj não atua em cursos da área de saúde.

O Enade 2017 completa um ciclo com resultados separados de EaD e presenciais, contemplando todos os cursos. A Figura 4 compara o Enade proporcional de EaD de todo o ciclo 2015-2017 para as vinte IES com o maior número de alunos matriculados em EaD em 2017.

\author{
FACULDADE EDUCACIONAL DALAPA \\ UNIVERSIDADE METROPOLITANA DE SANTOS \\ UNIVERSIDADE DE SANTO AMARO \\ CENTRO UNIVERSITARIO DA GRANDE DOURADOS \\ UNIVERSIDADE ANHANGUERA - UNIDERP \\ UNIVERSIDADE NORTE DO PARANÁ \\ CENTRO UNIVERSITÁRIO LEONARDO DA VINCI \\ CENTRO UNIVERSITÁFAO ESTÁCIO DE RIBEIRAO PRETO \\ UNIVERSIDADE PAULISTA \\ UNIVERSIDADE DE UBERABA \\ UNIVERSIDADE DE FRANCA \\ UNIVERSIDADE CIDADE DE SAOO PAULO \\ CENTRO UNIVERSITARIO INTERNACIONAL \\ CENTRO UNIVERSITÁRIO CLARETIANO \\ UNIVERSIDADE CRUZEIRO DO SUL. \\ CENTRO UNIVERSITÁRIO DE MARINGÁ - UNICESUMAR \\ UNIVERSIDADE NOVE DE JULHO \\ UNIVERSIDADE ESTACIO DE SA \\ UNIVERSIDADE ANHEMBI MORUMBI \\ UNIVERSIDADE FEDERAL FLUMINENSE
}

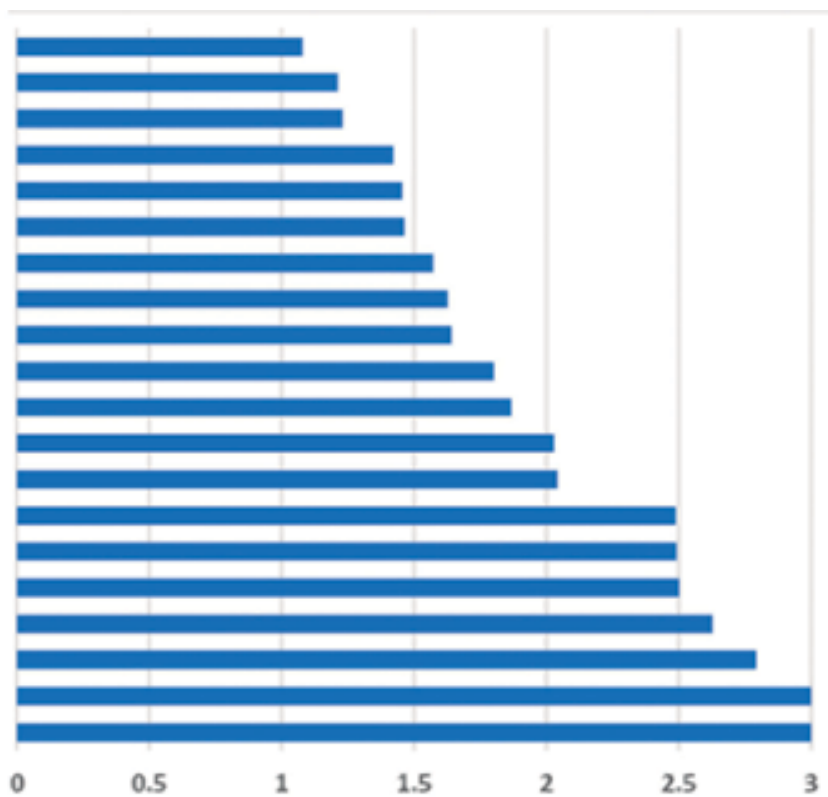

Figura 4: Enade proporcional de EaD do Ciclo 2015-2017 das 20 IES com o maior número de matrículas de EaD em 2017.

É preocupante observar que onze das 20 IES com maior oferta em EaD, que têm 987.306 alunos de EaD matriculados em 2017 (56,1\% das matrículas de EaD), apresentam um Enade proporcional para o ciclo 2015-2017 abaixo de 1,945, ou seja, um conceito Enade discreto 2. Em particular, sete dessas 20 IES (com 735.695 alunos de EaD em 2017, 41,2\% das matrículas) têm Enade proporcional para o ciclo 2015-2017 inferior a 1,6. Uma delas, com 34.865 alunos em EaD em 2017, tem conceito Enade proporcional para o ciclo 2015-2017 de apenas 1,08.

Por outro lado, é auspicioso observar que, das 20 IES com maior oferta de EaD, sete têm Enade com conceito discreto 3 e duas com conceito discreto 4. Outro fato positivo são os resultados de 2017 do Centro Universitário Internacional (162.243 alunos de EaD em 2017), que em 2015 e 2016 apresentou um conceito Enade proporcional discreto 2, mas alcançou no ciclo 2015-2017 conceito discreto 3.

Por outro lado, causa preocupação analisar a diferença, no Enade presencial e no Enade EaD para o ciclo 2015-2017, das 10 IES com maior número de matrículas, conforme mostra a Tabela 7. 
Tabela 7: Enade proporcional do ciclo 2015-2017 para as dez IES com maior oferta de EaD.

\begin{tabular}{|l|c|c|c|c|}
\hline & \multicolumn{2}{|c|}{ Matrículas em 2017} & \multicolumn{2}{c|}{$\begin{array}{c}\text { Enade proporcional para o } \\
\text { ciclo 2015-2017 }\end{array}$} \\
\hline & Presencial & EaD & Presencial & EaD \\
\hline Universidade do Norte do Paraná & 14.732 & 344.863 & 2,33 & 1,46 \\
\hline Universidade Paulista & 217.088 & 163.517 & 2,62 & 1,64 \\
\hline Centro Universitário Internacional & 2.839 & 162.234 & 2,17 & 2,04 \\
\hline Universidade Anhanguera - Uniderp & 17.608 & 161.181 & 1,48 & 1,45 \\
\hline Centro Universitário Leonardo da Vinci & 1.473 & 142.219 & 2,49 & 1,57 \\
\hline Universidade Estácio de Sá & 125.760 & 93.953 & 2,27 & 2,79 \\
\hline Centro Universitário de Maringá - Unicesumar & 11.353 & 64.142 & 3,03 & 2,50 \\
\hline Centro Universitário Estácio de Ribeirão Preto & 4.506 & 36.144 & 2,42 & 1,63 \\
\hline Universidade de Franca & 11.216 & 35.769 & 2,04 & 1,87 \\
\hline Faculdade Educacional da Lapa & 191 & 34.865 & 2,07 & 1,08 \\
\hline
\end{tabular}

Podemos observar, de maneira geral, fortes diferenças entre os resultados do Enade presencial e o de EaD para o ciclo 2015-2017. Nota-se também fraco desempenho dos alunos no Enade para o ciclo 20152017 em sete das 10 IES com maior oferta de EaD em 2017. Separamos o resultado do ciclo 2015-2017 entre essas sete IES e as demais 137 que foram avaliadas no ciclo 2015-2017 (Tabela 8).

Tabela 8: Enade proporcional para o ciclo 2015-2017 separando os resultados de sete IES das demais que foram avaliadas pelo Enade neste ciclo.

\begin{tabular}{|c|c|c|c|c|c|c|}
\hline & \multicolumn{2}{|c|}{$\begin{array}{c}\text { Alunos matriculados } \\
\text { em } 2017\end{array}$} & \multicolumn{2}{|c|}{$\begin{array}{l}\text { \% de alunos } \\
\text { matriculados em } 2017\end{array}$} & \multicolumn{2}{|c|}{$\begin{array}{l}\text { Enade proporcional } \\
\text { ciclo 2015-2017 }\end{array}$} \\
\hline & Presencial & EaD & Presencial & EaD & Presencial & EaD \\
\hline Todas as IES & 6.520 .423 & 1.759 .250 & 100,0 & 100,0 & 2,40 & 1,84 \\
\hline $\begin{array}{l}\text { Sete das } 10 \text { IES com } \\
\text { maior número de matrí- } \\
\text { culas em EaD }\end{array}$ & 266.814 & 918.558 & 4,1 & 52,2 & 2,46 & 1,51 \\
\hline $\begin{array}{l}\text { Todas as demais } 137 \text { IES } \\
\text { avaliadas pelos Enade } \\
2015-2017\end{array}$ & 2.144 .660 & 759.714 & 32,9 & 43,2 & 2,68 & 2,16 \\
\hline
\end{tabular}

A Tabela 8 mostra um desempenho no Enade global dos alunos presenciais de 2,40, superior àquele alcançado pelos alunos de EaD, de 1,84. Um dos principais fatores dessa diferença é a oferta de apenas 7 IES que detêm 52\% de todas as matrículas, têm desempenho no presencial de 2,46 e na EaD de 1,51. Excetuando a oferta dessas IES, o desempenho dos alunos de EaD nas outras 147 IES sobe para 2,16.

\subsection{Resultados específicos do Enade 2017}

A Tabela 9 resume os dados dos dez cursos com maior número de alunos de EaD avaliados no Enade de 2017. 
Tabela 9: Participantes, alunos matriculados e Enade proporcional dos cursos com o maior número de alunos em EaD avaliados no Enade 2017.

\begin{tabular}{|l|c|c|c|c|c|c|}
\hline & \multicolumn{2}{|c|}{ Participantes 2017 } & \multicolumn{2}{c|}{ Matriculas 2017 } & \multicolumn{2}{c|}{ Enade proporcional 2017 } \\
\hline \multicolumn{1}{|c|}{ Curso } & Presencial & EaD & Presencial & EaD & Presencial & EaD \\
\hline Pedagogia & 55.077 & 57.233 & 270.733 & 412.270 & 2,4 & 1,86 \\
\hline Educação Física & 23.629 & 3.971 & 224.567 & 73.867 & 2,43 & 1,63 \\
\hline Matemática & 8.137 & 2.891 & 53.332 & 36.375 & 2,09 & 1,86 \\
\hline História & 11.603 & 4.126 & 57.272 & 36.254 & 2,63 & 2,15 \\
\hline $\begin{array}{l}\text { Análise e Desenvolvi- } \\
\text { mento de Sistemas }\end{array}$ & 7.655 & 1.689 & 54.184 & 31.234 & 2,52 & 1,97 \\
\hline Geografia & 8.916 & 2.042 & 40.965 & 19.773 & 2,61 & 1,97 \\
\hline Ciências Biológicas & 17.246 & 2.227 & 89.410 & 17.932 & 2,47 & 1,92 \\
\hline $\begin{array}{l}\text { Gestão da Tecnologia } \\
\text { da Informação }\end{array}$ & 1.828 & 1.410 & 13.156 & 14.579 & 2,65 & 2,74 \\
\hline $\begin{array}{l}\text { Engenharia de } \\
\text { Produção }\end{array}$ & 20.007 & 934 & 126.473 & 14.123 & 2,39 & 1,77 \\
\hline Letras - Português & 2.436 & 1.286 & 14.121 & 11.864 & 2,31 & 1,8 \\
\hline
\end{tabular}

Observa-se que a diferença de desempenho entre os alunos dos cursos presenciais e os de EaD é superior na maioria desses cursos. O curso de Pedagogia é aquele que reúne o maior número de alunos, com um total de 683 mil estudantes, dos quais 412 mil $(60,3 \%)$ em cursos de EaD. A seguir comparamos os resultados do Enade proporcional para esse curso por categoria administrativa.

Tabela 10: Resultados do curso de Pedagogia para o Enade proporcional de 2017 por categoria administrativa.

\begin{tabular}{|l|c|c|c|c|c|c|}
\hline & \multicolumn{2}{|c|}{ Participantes $\mathbf{2 0 1 7}$} & $\begin{array}{c}\text { Quantidade de matriculas do } \\
\text { curso em 2017 }\end{array}$ & \multicolumn{3}{c|}{ Enade proporcional 2017 } \\
\hline & Presencial & EaD & Presencial & EaD & Presencial & EaD \\
\hline Privada & 36.029 & 53.022 & 179.627 & 388.545 & 2,30 & 1,81 \\
\hline Pública estadual & 9.052 & 1.315 & 44.001 & 11.317 & 2,49 & 2,77 \\
\hline Pública federal & 8.710 & 2.546 & 41.251 & 11.248 & 2,76 & 2,60 \\
\hline
\end{tabular}

É uma situação alarmante constatar que, de um total de 683 mil alunos dos cursos de Pedagogia (presencial e EaD), 389 mil alunos das IES particulares estejam realizando cursos de EaD com Enade proporcional global de 1,81 (conceito discreto 2), com marcante diferença em relação ao desempenho dos cursos presenciais. Um fato positivo é que o Enade proporcional das IES públicas nas duas modalidades são próximos.

Vejamos o conceito contínuo das 10 principais ofertas do curso de Pedagogia. 
FACULDADE EDUCACIONAL DA LAPA

UNIVERSIDADE DE SANTO AMARO

UNIVERSIDADE METROPOLITANA DE SANTOS

UNIVERSIDADE TIRADENTES

CENTRO UNIVERSITARIO DA GRANDE DOURADOS

CENTRO UNIVERSITÁRIO ESTACIO DE RIBEIRAOO PRETO

UNIVERSIDADE ANHANGUERA - UNIDERP

CENTRO UNIVERSITARIO LEONARDO DA VING

UNIVERSIDADE NORTE DO PARANA

UNIVERSIDADE DE UBERABA

UNIVERSIDADE PAULISTA

CENTRO UNIVERSITARIO HERMINIO OMETTO

CENTRO UNIVERSITARIO DE MARINGA - UNICESUMAR

UNIVERSIDADE DE FRANCA

UNIVERSIDADE CIDADE DE SÃO PAULO

CENTRO UNIVERSITARIO INTERNACIONAL

UNIVERSIDADE CRUZEIRO DO SUL

UNIVERSIDADE NOVE DE JULHO

UNIVERSIDADE ESTÁCIO DE SÁ

UNIVERSIDADE DO ESTADO DO RIO DE JANEIRO

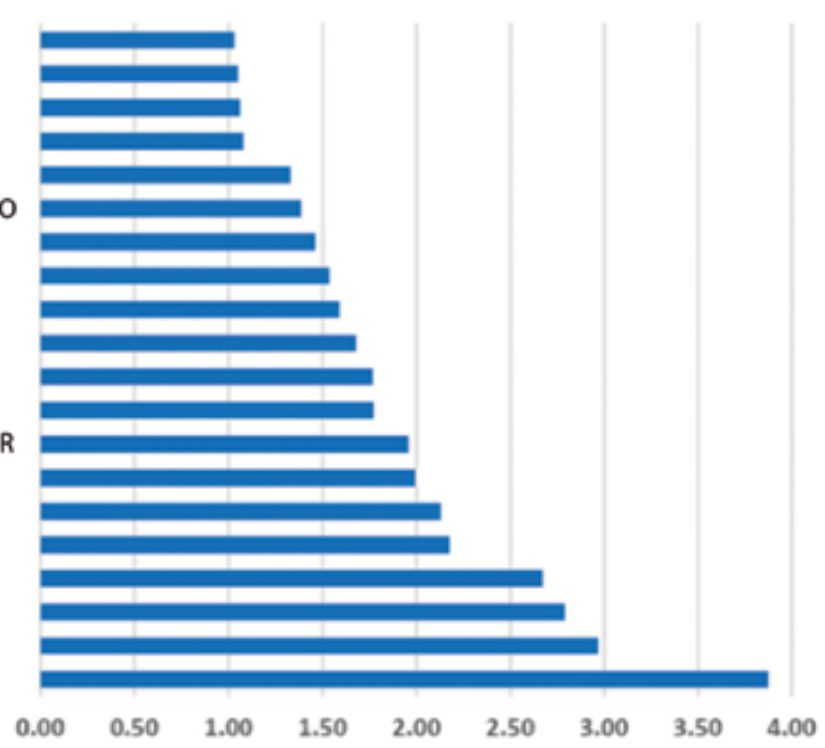

Figura 5: Enade 2017 do curso de Pedagogia com EaD para as 10 IES com o maior número de alunos.

Foram 203.602 mil alunos de EaD matriculados em 2017 nos cursos de Pedagogia de nove IES com Enade inferior a 1,6, o que representa metade dos alunos que utilizam EaD (404.850 mil) e 30\% de todos os alunos do país nas duas modalidades (661.034 alunos). Cabe ainda chamar a atenção de que 37.517 alunos de Pedagogia com EaD estão matriculados em quatro IES com Enade inferior a 1,1.

Situações destoantes também são encontradas em outros cursos avaliados no Enade 2017, como o perfil do curso de Matemática, cujas principais ofertas apresentamos na Figura 6.

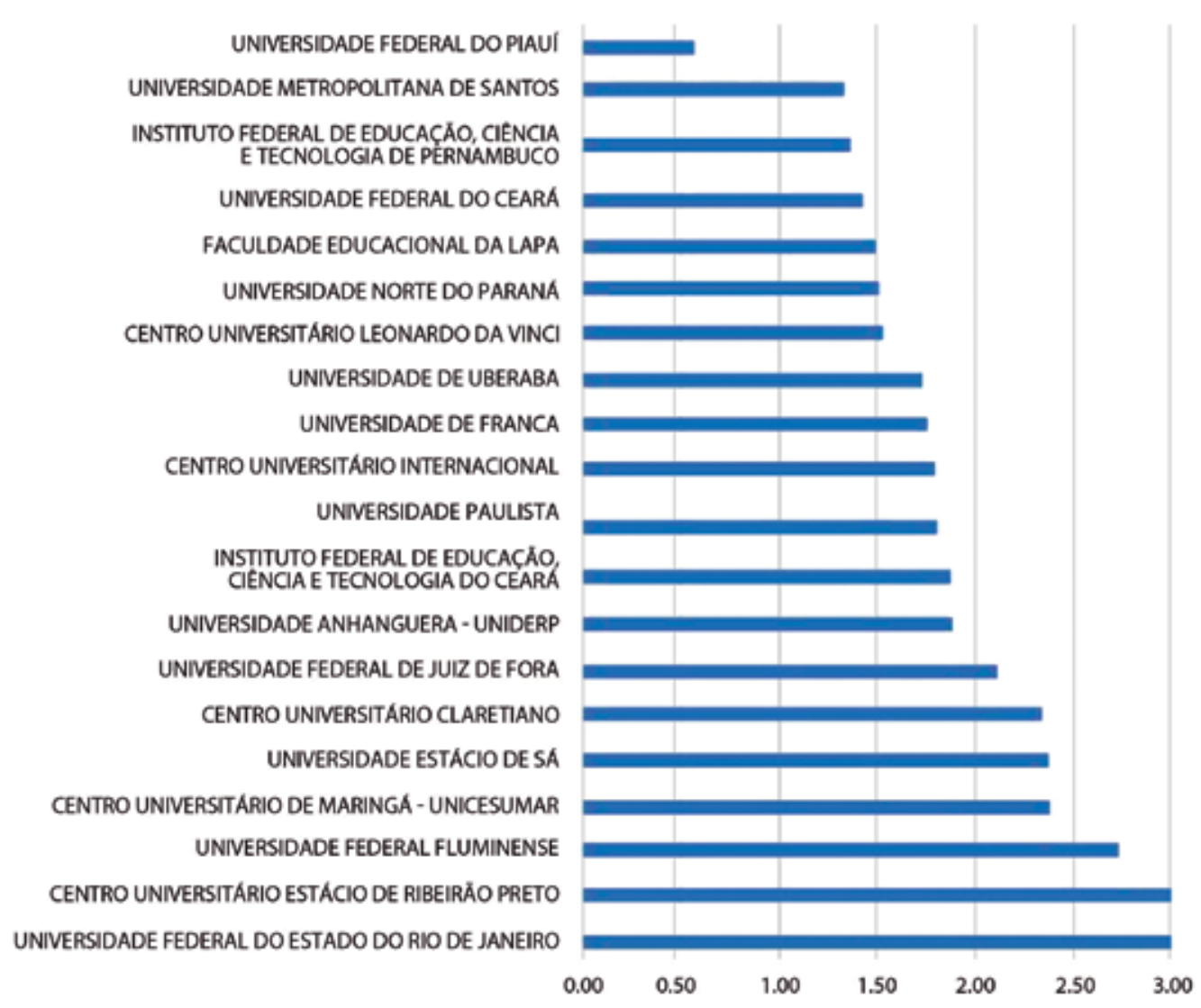

Figura 6: Enade de 2017 das principais ofertas do curso de Licenciatura em Matemática com EaD. 
A julgar pelos resultados do Enade, a formação na área de Matemática em EaD, embora um pouco melhor que a de Pedagogia, também se apresenta como problemática: cerca de um quarto dos alunos de Matemática do país (23.864 mil) estão matriculados em cursos de EaD com conceito Enade abaixo de 1,945 , ou seja, conceito discreto 2.

\section{Considerações Finais}

Apenas a partir de 2015 o Inep publicou os resultados do Enade de EaD separados daqueles dos cursos presenciais. Em 2017 completamos um primeiro ciclo de três anos do Enade abarcando todas as carreiras, com 175.543 alunos participantes de 877 cursos de EaD, pertencendo a um total de 144 diferentes instituições de Ensino Superior. Observamos que para a grande maioria dos cursos e das IES os alunos de EaD e dos cursos presenciais têm desempenho equivalente, confirmando a tese de que a oferta de EaD e presencial não deve apresentar diferenças significativas de qualidade.

Entretanto, devido à alta concentração de alunos em poucas IES com baixo desempenho no Enade, o Enade proporcional para todos os cursos de EaD do ciclo 2015-2017 é de 1,81, enquanto o resultado dos cursos presenciais é de 2,27, indicando problemas que podem comprometer uma modalidade que vem contribuindo significativamente para o desenvolvimento do país. Causa especial preocupação que sete das 10 IES que detêm o maior número de matrículas em EaD em 2017 (52\% do total) tenham um Enade proporcional para o ciclo 2015-2017 de apenas 1,51, dado esse que fica ainda mais inaceitável quando compararmos com o Enade proporcional dos alunos presenciais dessas mesmas IES, de 2,46.

Esses resultados levam aos seguintes questionamentos:

i. Quais as consequências dessa concentração de matrículas na qualidade do ensino oferecido aos alunos por nossas IES públicas e privadas?

ii. Quais as consequências dessa concentração de matrículas no desenvolvimento das diferentes opções de metodologia para a EaD?

iii. Os alunos têm, de fato, diferentes opções de oferta, especialmente em municípios menores?

Não dispomos hoje de uma avaliação adicional que possa trazer alguma luz a essa importante questão, uma vez que nem o Conceito Provisório de Curso (CPC), tampouco o Conceito Geral de Curso são adequados à modalidade EaD (Bielschowsky, 2018).

O MEC realizou entre 2007 e 2010 um amplo processo de supervisão para aquelas IES com maior número de alunos em EaD ou que apresentavam indícios de problemas de qualidade na oferta de seus cursos, procedimento que foi descontinuado em 2011. Contávamos à época com a colaboração de cerca de 650 professores de nossas universidades públicas e privadas que, de maneira geral, já atuavam em EaD e do apoio de técnicos da Secretaria de Educação a Distância (Seed/MEC).

A avaliação da oferta de EaD de uma IES se iniciava com a coleta de um grande conjunto de informações, tais como presença dos alunos em atividades didáticas na plataforma, densidade dos conteúdos impressos e digitais à disposição dos alunos, processo de avaliação dos alunos, infraestrutura, relação aluno/professor e aluno/(professor + tutor) para cada curso e equipe multidisciplinar. Em seguida, de posse desses elementos, os colaboradores visitavam a IES e parte de seus polos, conversando com os professores, técnicos e alunos. O conjunto de informações coletadas e os relatórios das visitas dos colaboradores permitiam alcançar uma visão sistêmica da oferta de EaD da IES. 
Foram identificados os seguintes problemas principais durante o processo de supervisão:

1. Desconexão da universidade com os alunos: atividades acadêmicas terceirizadas, às vezes mesmo por um terceirizado do terceirizado.

2. Alguns cursos não eram, na prática, cursos de graduação:

i. O material didático não tinha densidade para um curso de graduação; por exemplo, disciplinas com 40 páginas de material impresso e pouco ou nenhum material complementar;

ii. Avaliação realizada nesse contexto de conteúdo, ou seja, não exigia do estudante conhecimentos compatíveis com um curso de graduação.

3. Avaliações desconectadas dos docentes das universidades. Por exemplo: provas objetivas corrigidas automaticamente, em cima de um conteúdo aligeirado.

4. Alunos com deficiências graves de escrita formam-se em carreiras como Pedagogia ou licenciatura em Letras.

5. Falta de apoio ao estudante: encontramos casos em que o estudante não dispunha de tutoria presencial e a tutoria a distância era quase inexistente.

6. Polos de apoio presencial sem adequação mínima para oferta de Educação Superior, não configurando um ambiente de convivência acadêmica.

Advogamos, diante destes resultados muito preocupantes do Enade de EaD no ciclo 2015-2017 de algumas IES, três medidas urgentes:

i. Os cursos que apresentaram conceito Enade inferior a 1,945 (conceitos discretos 1 ou 2) devem ser temporariamente impedidos de oferecer novas matrículas;

ii. Deve ser instalado um amplo processo de supervisão em IES com cursos que apresentem baixo desempenho de seus alunos de EaD no Enade;

iii. Deve ser feita a revisão do CPC e do CGC para refletir a realidade dos cursos de EaD, como levar em conta a relação aluno/(tutor + professor), a qualificação dos tutores, a densidade de conteúdo contido nos materiais didáticos e na avaliação, entre outros.

Sugerimos que esse problema seja amplamente discutido, visando construir convergências em torno de uma política mais ampla e necessária. Em nosso entendimento, essa discussão deveria envolver os seguintes órgãos:

i. Conselho Nacional de Educação - CNE

ii. Secretaria de Regulação e Supervisão da Educação Superior (Seres), do MEC;

iii. Secretaria de Ensino Superior (SESU), do MEC;

iv. Abed (Associação Brasileira de Educação a Distância);

v. Unirede (Associação de Educação a Distância das Universidades Públicas);

vi. Associações que representam as universidades brasileiras, em particular Conselho de Reitores das Universidades Brasileiras - CRUB, Associação Nacional dos Dirigentes das Instituições Federais de Ensino Superior - Andifes, Associação Brasileira dos Reitores das Universidades Estaduais e Municipais - Abruem, e Conselho Nacional das Instituições da Rede Federal de Educação Profissional, Científica e Tecnológica - Conif.

Concluímos reiterando mais uma vez a importância da EaD para o desenvolvimento de pessoas que têm nessa modalidade sua grande oportunidade de crescer profissionalmente e para o desenvolvimento do país, uma vez que permite expandir sem fronteiras a abrangência de nossas instituições de Ensino Superior. Comprovamos que, também no Brasil, a EaD pode ter qualidade equivalente àquela do ensino presencial, como mostram os resultados do Enade para inúmeras instituições. 
Os resultados do Enade indicam, entretanto, baixa qualidade na oferta de algumas poucas IES que de maneira geral ficam distantes dos resultados do Enade de seus próprios cursos presenciais. Precisamos enfrentar urgentemente essa questão, que pode jogar por terra o propósito de aumentar o envolvimento da população no Ensino Superior em EaD e ajudar a construção de um país melhor.

\section{Referências Bibliográficas}

Australasian Council of Open, Distance and e-Learning - Acode (n. d.). Acesso em 18 dez. 2017. Disponível em: https://www.acode.edu.au/

Adams Becker, S., Cummins, M., Davis, A., Freeman, A., Hall Giesinger, C. \& Ananthanarayanan, V. (2017). NMC Horizon Report: 2017 Higher Education Edition. Austin: The New Media Consortium

Brasil. Decreto n. 9.057, de 26 de maio de 2017. Diário Oficial da União, Poder Legislativo, Brasília, 25 maio 2017.

Bielschowsky, C. (2017). Consórcio Cederj: A História da Construção do Projeto. EaD em Foco, 7(2). doi: https://doi.org/10.18264/eadf.v7i2.652

Bielschowsky, C. (2018). Qualidade na Educação Superior a Distância no Brasil: onde estamos, para onde vamos? EaD em Foco, 8(1). doi: https://doi.org/10.18264/EaDf.v8i1.709

Caled. Instituto Latinoamericano y del Caribe de Calidad en Educación Superior a Distancia (n. d.) Acesso em 18 dez. 2017. Disponível em: http://www.caled-EaD.org

Chea. Council for Higher Education Accreditation (n. d.). Acesso em 18 dez. 2017. Disponível em: http:// www.chea.org/

EaDtu - e-xellence. The European quality benchmark for online, open and flexible education. EADTU - European Association of Distance Teaching Universities (n. d.). Acesso em 18 dez. 2017. Disponível em: http://e-xcellencelabel.EaDtu.eu/

ICDE. International Council for Open and Distance Education (2015). Quality models in online and open education around the globe: State of the art and recommendations. Project coordinator: EADTU - EUropean Association of Distance Teaching Universities. Acesso em 01 dez. 2017. Disponível em https:// www.icde.org/quality-models-in-online-and-open-education-around-the-globe.

Instituto Nacional de Estudos e Pesquisas Educacionais Anísio Teixeira - Inep (n. d.). Microdados do Censo de Educação Superior 2005-2017 e Microdados do Enade. Acesso em 29 jan. 2018. Disponível em: http:// portal.inep.gov.br/web/guest/microdados.

Jarvis, Darryl S. L. (2014). Regulating higher education: quality assurance and neo-liberal managerialism in higher education - a critical introduction. Policy and Society, 33(3), 133-166. https://doi.org/10.1016/j. polsoc.2014.09.005

MEC. Portaria Normativa no 11/2017. Diário Oficial da União, 117, 21 de junho de 2017. Disponível em: http://portal.mec.gov.br/index.php?option=com_docman\&view=download\&alias=66431-portarianormativa-11-pdf\&category slug=maio-2017-pdf\&ltemid=30192.

MEC. Referenciais de Qualidade para EaD. 2003 e 2007 (n. d.). Disponível em: http://portal.mec.gov. br/par/193-secretarias-112877938/seed-educacao-a-distancia-96734370/12777-referenciais-dequalidade-para-EaD.

Nielsen, D. H. (2010). Quality assessment and quality assurance in distance teacher education. Distance Education, 18, 284-317. 
Petters, O. Learning and teaching in distance education: Analyses and interpretations from an international perspective (2001). London: Kogan Page. ISBN 0-7494-3594-1.

Quezada, M. M. \& Rama, C. (n. d.) Los problemas de la evaluación de la Educación a Distancia en América Latina y el Caribe. Disponível em http://www.caled-EaD.org/publicaciones/libros-caled.

Quezada, M. M. \& Muñoz, P. A. (n. d.). Leyes, normas y reglamentos que regulan la Educación Superior a Distancia y en Línea en América Latina y el Caribe. 2. ed. Disponível em: http://www.caled-EaD.org/publicaciones/libros-caled. 